\title{
Synthesis of Carbon Nanofibers Using Carbon Monoxide DC Plasma at Room Temperature
}

\author{
Shinsuke Mori, Masanobu Fukuya and Masaaki Suzuki \\ Department of Chemical Engineering, Tokyo Institute of Technology \\ 2-12-1, O-okayama, Meguro-ku, Tokyo 152-8552 \\ Fax: 81-3-5734-2112, e-mail: smori@chemeng.titech.ac.jp
}

A low temperature synthesis of carbon nanofibers was demonstrated by a plasma-enhanced chemical vapor deposition (PECVD). A low temperature CO/Ar DC plasma was used in this study. Carbon films deposited on glass substrate during PECVD were characterized by scanning electron microscopy and Raman spectroscopy. The effect of discharge current and substrate location on the CNFs formation has been investigated. The results show that vertically aligned carbon nanofibers can be synthesized at even room temperature with optimum discharge conditions when the substrate is placed on the cathode. Key words: Carbon nanofiber, CO plasma, Room temperature synthesis, DC glow discharge, PECVD

\section{INTRODUCTION}

Carbon nanofibers (CNFs) as well as carbon nanotubes (CNTs) are the most promising materials as field emitters in flat panel display due to their low tum-on voltage and good current stability with chemical inertness and mechanical strength. Their high surface area makes CNTs/CNFs also attractive for applications such as electrochemistry, electrodes for fuel cells, and supercapacitors. For practical applications of CNTs/CNFs, a method for their synthesis at low temperatures is essential to allow direct deposition of $\mathrm{CNTs} / \mathrm{CNFs}$ on various substrates involving materials with low melting points, and a large number of studies on low temperature synthesis of CNFs/CNTs have been reported [1-5]. For example, Hofmann et al. demonstrated the low temperature synthesis of CNFs using a DC glow discharge plasma of $\mathrm{C}_{2} \mathrm{H}_{2}$ and $\mathrm{NH}_{3}$ and vertically aligned CNFs were successfully grown on a polyimide substrate at $200^{\circ} \mathrm{C}$ [6]. In the present study, we performed the low temperature synthesis of CNFs using $\mathrm{CO}$ plasma because a $\mathrm{CO}$ plasma has a attracting characteristic for low temperature CVD that disproportionation reaction of $\mathrm{CO}$ is enhanced by the vibrational excitation of $\mathrm{CO}$ caused by the vibrational energy pumping of $\mathrm{CO}$ in plasma at a low translational temperature condition [7-9].

\section{EXPERIMENTAL}

Figure 1 shows the schematic diagram of experimental apparatus. The quartz discharge tube has a $10 \mathrm{~mm}$ inner diameter, and there are two electrodes which are spaced $5 \mathrm{~cm}$ apart and connected to the DC power supply in the discharge tube; one of them is stainless steel sample stage with a diameter of $6 \mathrm{~mm}$ and the other is stainless steel rod with a diameter of $1.5 \mathrm{~mm}$. In this study, borosilicate glass substrates ( $4 \mathrm{~mm} \times 4 \mathrm{~mm}$ $x 0.2 \mathrm{~mm}$ ) with a thin Fe catalyst layer were used as substrates. The Fe catalyst layer was prepared using wet coating of the solution of Fe acetate. The solution was prepared by dissolving $\mathrm{Fe}$ acetate into ethanol so that the concentration of $\mathrm{Fe}$ was $0.01 \mathrm{wt} \%$ and then $0.1 \mathrm{ml}$ solution was dropped onto the substrates and dried in the atmosphere. The catalyst layer was pretreated by $\mathrm{H}_{2} / \mathrm{Ar}$ plasma for 5 minutes before CNFs synthesis and then a $\mathrm{CO} / \mathrm{Ar}$ glow discharge plasma was generated for the CNFs deposition. The detailed parameters for the deposition process are listed in Table $I$ and shown below: CO flow rate: $10 \mathrm{sccm}$, Ar flow rate: $10 \mathrm{sccm}$, pressure: $800 \mathrm{~Pa}$. The substrate temperature, $T s$, was monitored by a thermocouple placed below the substrate. The plasma emission was monitored by a spectrometer (Ocean Optics, HR4000). Carbon deposits grown on the substrates were observed by scanning electron microscopy (KEYENCE, VE-8800) and analyzed by Raman spectroscopy (JASCO, NRS-2100). (a)

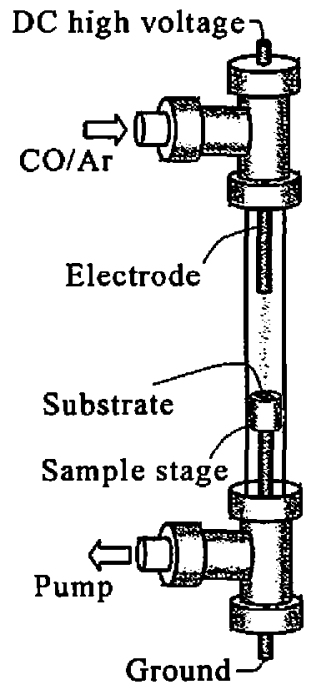

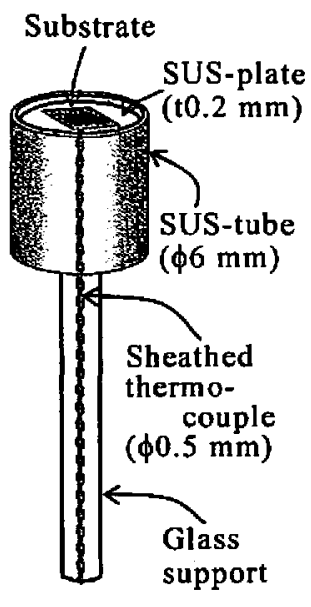

(b)
Fig.l Schematic diagram of experimental apparatus: (a) Plasma reactor and (b) Sample stage. 
Table I Experimental conditions and results

\begin{tabular}{lcccccc}
\hline & $\begin{array}{c}\text { Discharge } \\
\text { Current } \\
(\mathrm{mA})\end{array}$ & $\begin{array}{c}\text { Discharge } \\
\text { Voltage } \\
(\mathrm{kV})\end{array}$ & $\begin{array}{c}\text { Deposition } \\
\text { Time } \\
(\mathrm{min})\end{array}$ & $\begin{array}{c}\text { Sample } \\
\text { Temperature } \\
\left({ }^{\circ} \mathrm{C}\right)\end{array}$ & Sample position & $\begin{array}{c}\text { CNF } \\
\text { formation }\end{array}$ \\
\hline Sample (1) & 0.2 & 1.10 & 120 & 28 & Cathode & $\bigcirc$ \\
Sample (2) & 2.0 & 0.75 & 60 & 92 & Cathode & 0 \\
Sample (3) & 4.0 & 0.72 & 30 & 138 & Cathode & $\times$ \\
Sample (4) & 5.0 & 0.70 & 30 & 182 & Cathode $^{(\mathrm{a})}$ & $\times$ \\
Sample (5) & 2.0 & 0.75 & 60 & 39 & Anode $^{(3)}$ & $\times$ \\
Sample (6) & 2.0 & 0.75 & 60 & 44 & Positive Column $^{(\mathrm{b})}$ & $\times$ \\
\hline
\end{tabular}

(a) The substrate was placed on the sample stage but the polarity of electrodes was changed.

(b) The substrate was attached on the inner surface of discharge tube at positive column area and the substrate temperature was measured by a thermo-couple placed on the outer surface of discharge tube.

\section{RESULTS AND DISCUSSION}

Figure 2 shows the SEM images of carbon deposits after 30-120 minutes deposition time with different discharge current. When the discharge current was lower than $2.0 \mathrm{~mA}$, aligned carbon nanofibers were able to be synthesized. However, for higher discharge current conditions, the fibrous structure disappeared. Although the deposition rate of sample (3) seems to be lower than
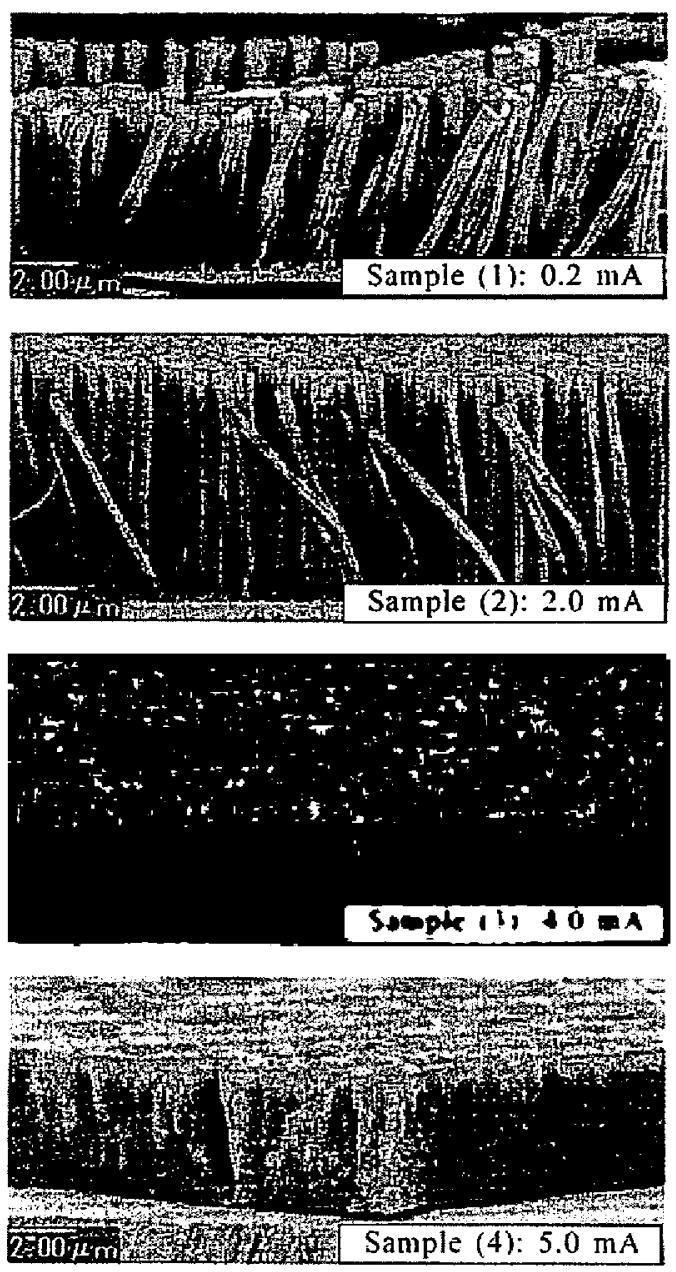

Fig.2 SEM images of samples (1) to (4). that of sample (2), the density and total carbon amount deposited in sample (3) would be higher than that in sample (2). As shown in Table 1 , the substrate was heated up by the discharge itself. However, the temperature of sample (1) increased very slightly and kept almost room temperature.

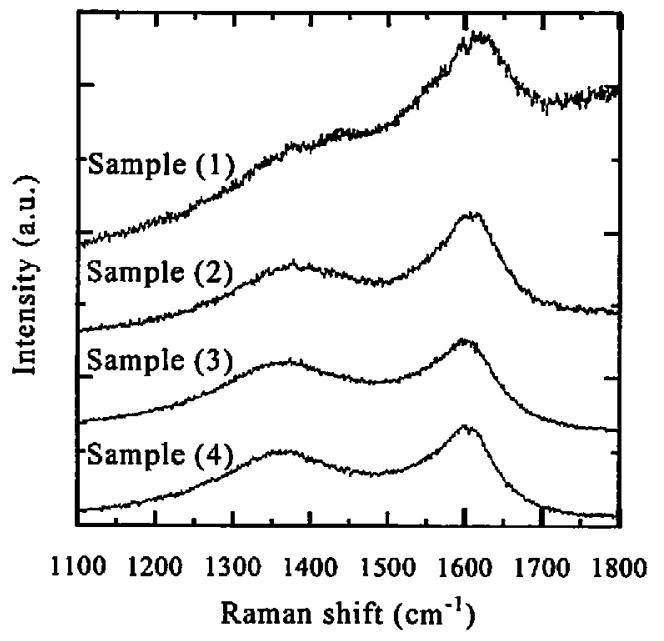

Fig.3 Raman spectra of samples (1) to (4) with same exposure time.

Figure 3 shows Raman spectra of the carbon materials formed on the glass substrates. The spectra for all samples present two peaks of carbon materials: the rather sharp G-band peak at approximately $1590 \mathrm{~cm}^{-1}$ which indicates crystalline graphene layers and the broad D-band peak at $1350 \mathrm{~cm}^{-1}$ which indicates the existence of defective graphene layers such as amorphous carbon layers. The intensity ratio of G-band and D-band signifies the degree of graphitization of CNFs. As shown in Fig. 3, the G/D ratio decreases with increasing current density. It means that for higher discharge current conditions, amorphous carbon deposits increased and it would be the reason for the disappearance of fibrous structure.

In this study, the effect of substrate position has also been investigated. The experimental conditions for samples (2), (5), and (6) were same but the positions of 

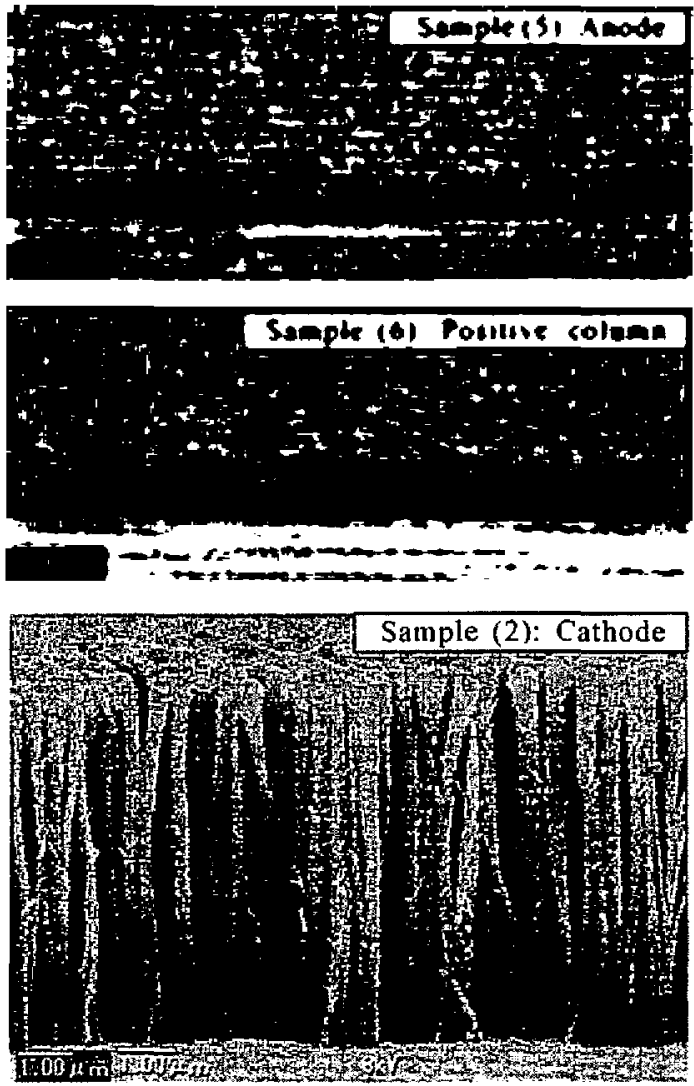

Fig.4 SEM images of samples (5), (6), and (2).

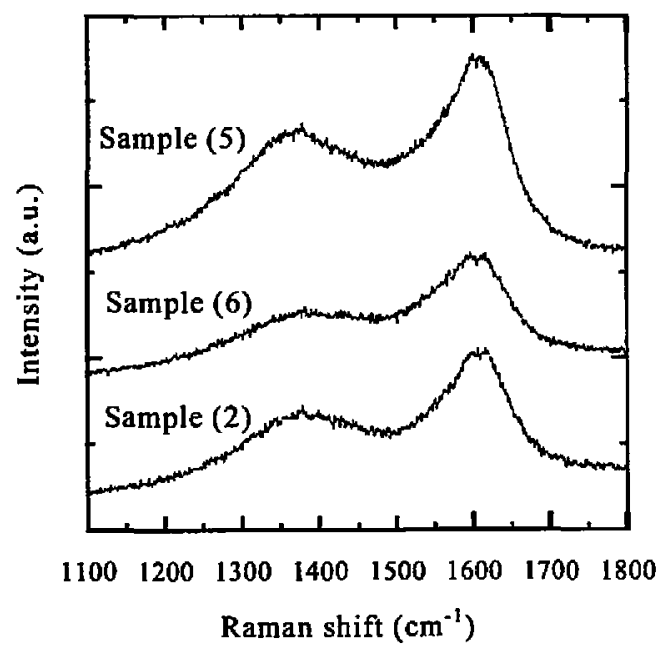

Fig.5 Raman spectra of samples (5), (6), and (2) with same exposure time.

substrates were different: Samples (2), (5), and (6) were placed in the cathode, anode, and positive column area, respectively. SEM images and Raman spectra of samples (2), (5), and (6) are shown in Fig. 4 and Fig. 5, respectively. Among three samples, the intensity of Raman spectra for sample (2) indicates medium value and the G/D ratios are almost same for three samples. However, CNFs are not observed for samples (5) and (6).
The substrate biasing to the negative potential would be essential for low temperature synthesis of CNFs using CO plasma.

Figure 6 shows a typical emission spectrum from $\mathrm{CO} / \mathrm{Ar}$ plasma. The strong $\mathrm{CO}$ Angstrom band spectra around $500 \mathrm{~nm}$ and weak $C_{2}$ swan band spectra at 563.6 $\mathrm{nm}$ and $\mathrm{C}$ atom spectra at $247.9 \mathrm{~nm}$ have been observed. The emission intensity of $\mathrm{C}_{2}$ and $\mathrm{C}$ and $\mathrm{C} / \mathrm{C}_{2}$ intensity ratio are plotted for different discharge current and sample position in Fig. 7 and 8, respectively.

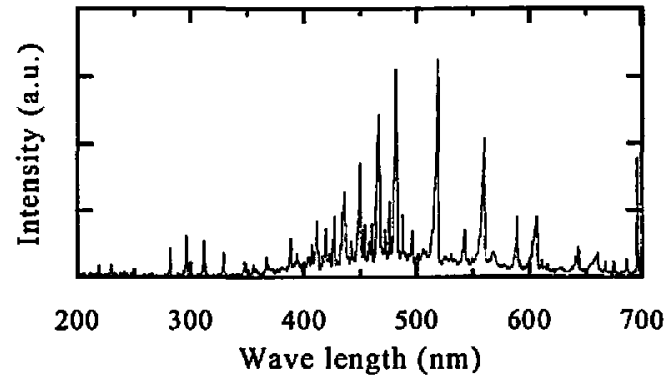

Fig.6 Typical emission spectra of CO/Ar plasma with $2.0 \mathrm{~mA}$ discharge current.

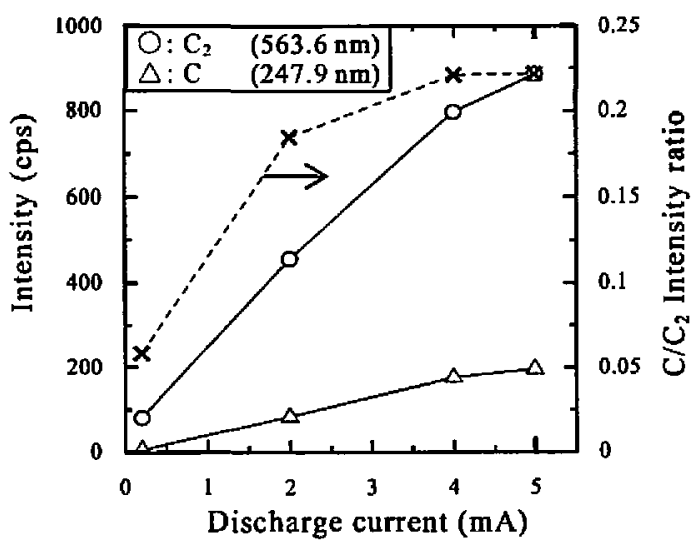

Fig.7 Emission intensity of $\mathrm{C}$ and $\mathrm{C}_{2}$ from $\mathrm{CO} / \mathrm{Ar}$ plasma.

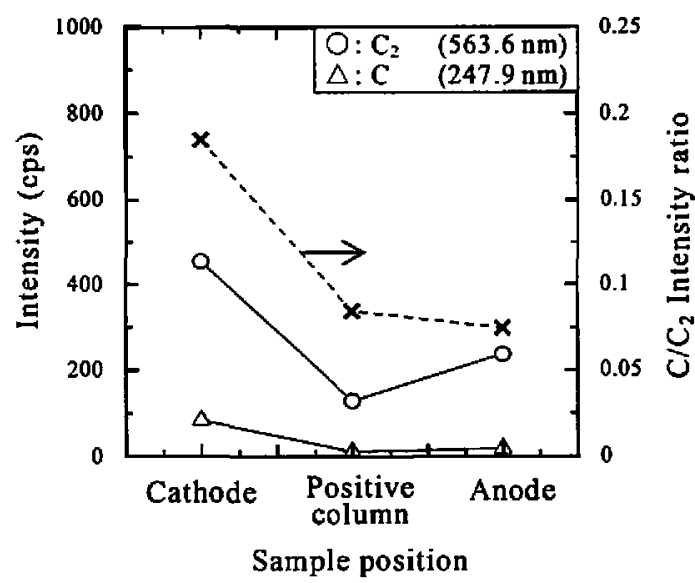

Fig.8 Emission intensity of $\mathrm{C}$ and $\mathrm{C}_{2}$ from $\mathrm{CO} / \mathrm{Ar}$ plasma. 
It is presumed from Fig. 7 that the excess $C_{2}$ and $C$ formation, especially atomic carbon formation, was enhanced by the increased discharge current and would result in the formation of amorphous carbon deposits. On the other hand, as shown in Fig. 8, although the $\mathrm{C}$ and $\mathrm{C}_{2}$ intensity from positive column and anode are not higher than that from cathode and the $\mathrm{C} / \mathrm{C}_{2}$ intensity ratio is almost constant for the different positions, CNFs were able to be synthesized only at cathode. Therefore, the disappearance of fibrous structure in the positive column and anode are mainly attributed to their inadequate substrate biasing.

As for a low temperature growth model for PECVD of CNFs, Hofmann et al. suggested [10] that the rate-determining step is not diffusion of carbon through the catalyst particle bulk which was proposed by Baker et al. [11] and is generally well accepted at high temperature conditions, but diffusion of carbon on the catalyst surface. In this surface diffusion model, carbon atoms adsorbed at the top surface of the metal particle can diffuse along the surface, where their motion is much faster than balk diffusion and then segregates at the bottom of the particle, forming graphitic planes. These graphitic basal planes are parallel to the metal surface and the orientation angle between the graphite basal planes and the tube axis is not zero, which results in the disappearance of tubular structure of CNFs. From this point we might go on to characterize the morphology of CNFs synthesized with various growth temperatures using transmission electron microscopy.

\section{CONCLUSION}

A low temperature synthesis of carbon nanofibers was performed by a plasma-enhanced chemical vapor deposition using a low temperature $\mathrm{CO} / \mathrm{Ar} \mathrm{DC}$ plasma. The carbon films deposited on glass substrate during PECVD were characterized by scanning electron microscopy and Raman spectroscopy. The results show that vertically aligned carbon nanofibers can be synthesized at even room temperature conditions with the smallest discharge current, $0.2 \mathrm{~mA}$, in the present study when the substrate is placed on the cathode.

\section{ACKNOWLEGEMENT}

This study was supported in part by a research grant from The Mazda Foundation.

\section{REFERENCES}

[I] Z. F. Ren, Z. P.Huang, J. W. Xu, J. H. Wang, P. Buxh, M. P. Siegal, P. N. Provencio, Science 282, 1105-1107 (1998).

[2] B. O. Boskovic, V. Stolojan, R.U.A. Khan, S. Haq and S.R.P. Silva, Nat. Mater. 1, 165-168 (2002).

[3] S. Honda, M. Katayama, K.-Y. Lee, T. Ikuno, S. Ohkura, K. Oura, H. Furuta, T. Hirao, Jpn. J. Appl. Phys., 42, L441-L443 (2003).

[4] S. Hofmann, B. Kleinsorge, C. Ducati, A. C. Ferrari, J. Robertson, Diamond Relat. Mater., 13, 1171-1176 (2004).

[5] S.-J. Kyung, Y.-H. Lee, C.-W. Kim, J.-H. Lee and G.-Y. Yeom, Carbon, 44, 1530-1534 (2006).

[6] S. Hofmann, C. Ducati, B. Kleinsorge, J. Robertson, Appl. Phys. Lett., 83, 4661-4663 (2003).

[7] M. Capitelli, "Nonequilibrium Vibrational Kinetics",
Springer, Berlin (1986).

[8] E. Plönjes, P. Palm, G. B. Viswanathan, V. V. Subramaniam, I. V. Adamovich, W. R. Lempert, H. L. Fraser, J. W. Rich, Chem. Phys. Lett., 352, 342-347 (2002).

[9] S. Mori, H. Akatsuka, M. Suzuki, J. Nucl. Sci. Technol., 38, 850-858, (2002).

[10] S. Hofmann, C. Ducati, J. Robertson, B. Kleinsorge, Appl. Phys. Lett., 83, 135-137 (2003).

[11] R. T. K. Baker, P. S. Harris, "Chemistry and Physics of Carbon, vol. 14", Marcel Dekker, New York, 83-165 (1978).

(Received December 20, 2006;Accepted February 14, 2007) 